\title{
ОРГАНИЗАЦИОННО-ПРАВОВЫЕ ВОПРОСЫ ПОДГОТОВКИ И ОСУЩЕСТВЛЕНИЯ АНТИКОРРУПЦИОННОГО МОНИТОРИНГА В СУБЪЕКТАХ РОССИЙСКОЙ ФЕДЕРАЦИИ
}

$\ni$ ффективное противодействие коррупции на региональном и муниципальном уровнях не возможно без формирования и развития такого диагностического инструмента как антикоррупционный мониторинг, который в настоящее время является важнейшим направлением совершенствования региональной антикоррупционной политики. Как показывает правовое регулирование и региональная антикоррупционная практика, сегодня в них возникли и активно развиваются множество механизмов оценки антикоррупционной деятельности, которые являются настолько разноплановыми, что сравнение одного региона с другим становится проблематичным. Это обусловлено как спецификой используемых технологических инструментов измерения, так и процедурными вопросами организации и проведения антикоррупционного мониторинга. Поэтому перед органами государственной власти субъектов РФ становится сложная и многоаспектная задача - создание и закрепление в нормативных правовых актах универсальной модели организации и проведения регионального антикоррупционного мониторинга. Решение этой сложной задачи необходимо для создания и функционирования многоуровневой системы диагностики состояния коррупции, её причин и эффективности мер антикоррупционной деятельности, для последующей корректировки региональной антикоррупционной политики.

Учитывая повышенную сложность задачи, стоящей перед региональными органами государственной власти и отсутствием глубоких научных разработок в области организации и проведения регионального антикоррупционного мониторинга встает очевидный вопрос каким образом можно создать универсальную организационно-правовую модель использования этого инструмента антикоррупционной политики. При отсутствии уникальных теоретических разработок организационно-правовой модели антикоррупционного мониторинга единственным методом её разработки становиться оценка накопленного опыта регионов по правовому регулированию, организации и проведению регионального и муниципального антикоррупционного мониторинга. Поэтому на первом этапе региональным органам государственной власти для глубокого понимания, описания и объяснения проблемы, оценки состояния её правового регулирования необходимо создание временной межведомственной рабочей группы по разработке концепции регионального антикоррупционного мониторинга из компетентных и добросовестных разработчиков.

На наш взгляд, концепция регионального антикоррупционного мониторинга представляет собой сформированные разработчиком идеи относительно целей, объекта, форм осуществления, содержания и будущего значения этого нормативного правового акта. В концепции должно быть указано действие этого нормативного правового акта во времени (постоянный, регулярный, временный) и пространстве (субъект РФ или муниципальное образование), по кругу лиц (органы государственной власти, органы местного самоуправления, институты гражданского общества, население). При этом необходимо, чтобы эта концепция регионального антикоррупционного мониторинга становилась неотъемлемой частью региональной правовой системы противодействия коррупции и не вступала с ней в противоречие.

Создание временной межведомственной рабочей группы по разработке концепции регионального антикоррупционного мониторинга потребует включения в её состав, помимо представителей органов государственной власти, органов местного самоуправления, представителей институтов гражданского общества и независимых экспертов в сфере противодействия коррупции из числа научных работников и профессорскопреподавательского состава образовательных учреждений высшего и дополнительного профессионального образования. Для этого необходимо нормативным правовым актом высшего должностного лица субъекта РФ утвердить положение о временной межведомственной рабочей группе по разработке концепции регионального антикоррупционного мониторинга, с указанием целей и задач стоящих ней, объема полномочий, срока деятельности и исчерпывающим перечнем (планом) организационных мероприятий. В этом же документе должен быть отражен персональный состав межведомственной рабочей группы с учетом 
специфики возложенных на неё задач. Этот этап в своё время был апробирован в органах исполнительной власти Астраханской области ${ }^{1}$, но по неизвестным нам причинам не получил дальнейшего развития в других субъектах РФ.

Основными задачами, стоящими перед межведомственной рабочей группой по разработке концепции регионального антикоррупционного мониторинга следует считать следующие направления. Во-первых, определить уполномоченный орган, который следует наделить функциями по организации и проведению антикоррупционного мониторинга в регионе, осуществив согласительные и иные процедуры. Во-вторых, разработать проект Порядка организации и проведения регионального антикоррупционного мониторинга. В-третьих, разработать проект Методики антикоррупционного мониторинга с обязательным перечислением основных и дополнительных показателей антикоррупционного мониторинга и технологии их обработки. В-четвертых, обсудить и предложить механизм взаимодействия и координации деятельности уполномоченного органа с региональными органами государственной власти, территориальными органами федеральных органов государственной власти, органами местного самоуправления, институтами гражданского общества и населением при осуществлении антикоррупционного мониторинга, то есть со всеми теми, кто будет реализовывать будущую концепцию. В-пятых, обосновать, обсудить и предложить меры по ресурсному (материальному, финансовому, информационному, интеллектуальному и т.д.) обеспечению проведения регионального антикоррупционного мониторинга. В-шестых, разработать и предложить механизмы использования результатов регионального антикоррупционного мониторинга. В-седьмых, разработать и предложить меры по совершенствованию правового регулирования регионального антикоррупционного мониторинга и обеспечению качественного его проведения.

Разумеется, что сформулированные нами задачи, стоящие перед межведомственной комиссией по разработке концепции регионального антикоррупционного мониторинга должны быть отражены в разрабатываемом документе, а также предложены ме-

\footnotetext{
1 О перечне мероприятий, необходимых для создания внутренней системы выявления и профилактики коррупционных рисков в исполнительных органах государственной власти Астраханской области: Распоряжение Правительства Астраханской области от 11 июня 2010 г. №245-пр // Документ официально опубликован не был и утратил свою силу 19 августа 2010 г., в соответствии с распоряжением Правительства Астраханской области от 19 августа 2010 г. №359-пр.
}

ханизмы их разрешения в ближайшей перспективе. Каждый из поставленных перед межведомственной комиссией вопросов является сложным, требует основательной проработки, согласования и обязательной логической аргументации. Ведь от того каким образом он будет разрешен во многом зависит успешность (результативность) применения этого регионального антикоррупционного диагностического инструмента. Например, наделение специальными полномочиями по организации и проведению антикоррупционного мониторинга органа государственной власти или органа местного самоуправления потребует изменения его организационно-штатной структуры. Такое изменение неизбежно повлечет за собой ряд правовых последствий, с одной стороны потребуется внесение изменений в положение об этом органе, о его структурных подразделениях и другие смежные с ними нормативные правовые акты, а с другой - поиск или подготовку (переподготовку) специалистов, способных качественно осуществлять антикоррупционный мониторинг и использовать его результаты.

При организации регионального антикоррупционного мониторинга автоматически на повестку дня встанет вопрос о взаимодействии между специализированным уполномоченным органом по организации и проведению мониторинга с региональными органами государственной власти, территориальными органами федеральных органов исполнительной власти, органами местного самоуправления, институтами гражданского общества и населением, а также координации деятельности по осуществлению антикоррупционного мониторинга. Создание надежного механизма направленного на разрешение этого вопроса является важнейшим направлением деятельности межведомственной рабочей группы.

Ещё сложнее решается вопрос о разработке проектов процедурного и технологического документов регионального антикоррупционного мониторинга Порядка и Методики (правил) его организации и проведения. Здесь не возможно простое заимствование названных документов из региональных нормативных правовых актов других субъектов РФ, где они применяются, поскольку они довольно часто отражают региональную специфику взаимодействия региональных, федеральных и муниципальных органов власти в сфере противодействия коррупции. Предпочтительнее будет выглядеть, если разработчики этих проектов позаимствуют из региональных нормативных правовых актов по организации и проведению антикоррупционного мониторинга, лишь структуру этих документов, уточнив соответствующие элементы процедурного или технологического характера, применительно к 
региональным особенностям функционирования органов государственной власти, органов местного самоуправления и институтов гражданского общества в сфере противодействия коррупции.

Любые благие начинания по организации и проведению регионального антикоррупционного мониторинга могут оказаться бесполезными или малопродуктивными, если они не будут достаточно обеспечены материальными, финансовыми, информационными и иными ресурсами. Поэтому разработчикам концепции регионального антикоррупционного мониторинга предстоит подготовить материалы по ресурсному обеспечению его проведения, подготовить и обосновать смету расходов (финансово-экономическое обеспечение) на проведение антикоррупционного мониторинга, внести предложения о внесении изменений в региональные нормативные правовые акты, регулирующие сложившиеся финнансово-бюджетные отношения.

Безусловно, результаты регионального антикоррупционного мониторинга представляют для органов государственной власти, органов местного самоуправления и институтов гражданского общества определенную ценность. Они используются при совершенствовании мер и инструментов региональной и муниципальной антикоррупционной политики (подготовки региональных и муниципальных антикоррупционных программ, оценка эффективности применения других антикоррупционных инструментов), но они могут использоваться с большой пользой и после их использования по прямому назначению. Например, при осуществлении антикоррупционной пропаганды и/или осуществлении антикоррупционного образования для описания и объяснения тенденций развития коррупции в регионе и эффективности мер противодействия ей, а также для повторного анализа данных при последующих исследованиях закономерностей развития коррупции в регионе и диалектики развития мер противодействия ей. Поэтому разработчикам концепции необходимо в этом организационно-правовом документе предусмотреть правовое регулирование дополнительного направления использования результатов регионального антикоррупционного мониторинга.

Разработка проекта региональной концепции антикоррупционного мониторинга и последующее её принятие компетентным на то органом государственной власти или должностным лицом потребует совершенствование регионального антикоррупционного законодательства и целого ряда подзаконных нормативных правовых актов. Поэтому разработчикам концепции потребуется дополнительная подготовка проектов нормативных правовых актов по внесению изменений в действующие норма- тивные правовые акты, направленные на организацию и проведение антикоррупционного мониторинга. В некоторых субъектах РФ понадобится корректировка регионального антикоррупционного законодательства, которая будет направлена на его изменение или дополнение в связи с использованием регионального и/или муниципального антикоррупционного мониторинга в антикоррупционной деятельности.

Естественно, утверждение концептуального документа по организации регионального антикоррупционного мониторинга должно происходить высшим должностным лицом органов исполнительной власти субъекта РФ путем принятия нормативного правового акта. Этот нормативный правовой акт может именоваться по-разному. На наш взгляд, предпочтительнее будет выглядеть его наименование следующим образом - «Об организации системы антикоррупционного мониторинга». Хотя оно может выглядеть или иным образом, но самое главное - в нем должны даваться поручения региональным органам государственной власти, территориальным органам федеральных органов государственной власти, органам местного самоуправления и иным субъектам антикоррупционного мониторинга, направленные на обеспечение его исполнения в полном объеме, надлежащим образом и в установленные сроки.

Примером нормативного правового акта, регулирующего вопросы организации регионального антикоррупционного мониторинга, может служить Указ Губернатора Ярославской области «Об осуществлении антикоррупционного мониторинга соблюдения требований законодательства о противодействии коррупции ${ }^{2}$. Этим нормативным правовым актом определен уполномоченный органа - Управление по противодействию коррупции, которое наделяется полномочиями по организации и проведению регионального антикоррупционного мониторинга, а органам исполнительной власти поручается обеспечение предоставления управлению информации, необходимой для его осуществления. Аналогичным образом решается вопрос по организации и проведению антикоррупционного мониторинга в Республике Татарстан в соответствии с Указом Президента Республики Татарстан по данному вопросу. В этом нормативном правовом акте определяется уполномоченный орган по проведению антикоррупционного мониторинга; им же наделен полномочиями Кабинет Министров Республики Татарстан по принятию нормативных

2 Об осуществлении антикоррупционного мониторинга соблюдения требований законодательства о противодействии коррупции: Указ Губернатора Ярославской области от 7 июня 2012 г. № 256 // Документ-Регион. - 2012. - 13 июня. 
правовых актов для решения процедурных вопросов его организации и проведения; даны поручения региональным органам государственной власти, территориальным органам федеральных органов исполнительной власти, органам местного самоуправления предоставлять необходимую информацию для проведения антикоррупционного мониторинга, а также утверждается Перечень основных показателей регионального антикоррупционного мониторинга ${ }^{3}$.

На втором этапе правового регулирования организации и проведения антикоррупционного мониторинга необходимы разработка и принятие нормативных правовых актов, регулирующих процедурные и технологические вопросы проведения антикоррупционного мониторинга - порядок, методику (методические рекомендации) или правила проведения регионального антикоррупционного мониторинга. Эти кодифицированные документы должны утверждаться компетентным на то региональным органом государственной власти или должностным лицом. Как показывает сравнительно-правовой анализ региональных нормативных правовых актов, регулирующих процедурные и технологические вопросы проведения антикоррупционного мониторинга, они принимаются чаще всего высшими региональными исполнительными органами государственной власти - правительством субъекта РФ. Примером тому могут служить нормативные правовые акты принятые Правительством Ярославской области ${ }^{4}$, Кабинетом Министров Республики

\footnotetext{
3 О мерах по организации и проведению мониторинга эффективности деятельности органов исполнительной власти Республики Татарстан, территориальных органов федеральных органов исполнительной власти по Республике Татарстан, органов местного самоуправления муниципальных районов и городских округов Республики Татарстан по реализации антикоррупционных мер на территории Республики Татарстан: Указ Президента Республики Татарстан от 23 марта 2011 г. №УП-148 // Сборник постановлений и распоряжений Кабинета Министров Республики Татарстан и нормативных актов республиканских органов исполнительной власти. - 2011. - №11. - №18. - Ст.0636

4 Об утверждении методики проведения антикоррупционного мониторинга цен на товары, услуги и при осуществлении закупок для нужд Ярославской области: Постановление Правительства Ярославской области от 26 августа 2011 г. №624 // Документ-Регион. - 2011. - 6 сентяб.; Об осуществлении антикоррупционного мониторинга соблюдения требований законодательства о противодействии коррупции: Постановление Правительства области от 12.09.2012 № 888-П // Документ-Регион. - 2012. - 21 сентяб.
}

Татарстан ${ }^{5}$, Правительством Ростовской области ${ }^{6}$, Правительством Республики Дагестан ${ }^{7}$ и Правительством Санкт-Петербурга8. Однако, не редко Порядок и/или Методику проведения антикоррупционного мониторинга могут принимать отдельные ведомства по специальному полномочию (Министерство юстиции Мурманской области), либо региональные специализированные совещательные, консультативные или координационные антикоррупционные органы (Ставропольский край ${ }^{9}$ ).

На третьем этапе правового регулирования организации и проведения антикоррупционного мониторинга необходимы разработка и принятие ведомственных и муниципальных нормативных правовых актов, направленных на информационное обеспечение проведения регионального антикоррупционного мониторинга. На этом этапе должны быть определены структурные подразделения и/или должностные лица, уполномоченные на организацию и проведение ведомственного или муниципального антикоррупционного мониторинга. В качестве примеров ведомственного реагирования на проведение антикорруп-

\footnotetext{
Об организации и проведении мониторинга эффективности деятельности органов исполнительной власти Республики Татарстан, территориальных органов федеральных органов исполнительной власти по Республике Татарстан, органов местного самоуправления муниципальных районов и городских округов Республики Татарстан по реализации антикоррупционных мер на территории Республики Татарстан: Постановление Кабинета Министров Республики Татарстан от 10 июня 2011 г. №463 // Сборник постановлений и распоряжений Кабинета Министров Республики Татарстан и нормативных актов республиканских органов исполнительной власти. - 2011. - №25. - Ст. 1081.

6 О порядке осуществления комиссией по противодействию коррупции в Ростовской области антикоррупционного мониторинга: Постановление Правительства Ростовской области от 19 апреля 2012 г. №300 // Наше время. - 2012. - 3 мая.

О порядке осуществления антикоррупционного мониторинга: Постановление Правительства Республики Дагестан от 20 апреля 2012 г. №119 // Собрание законодательства Республики Дагестан. - 2012. - №8. - Ст.312.

8 О Порядке проведения антикоррупционного мониторинга в Санкт-Петербурге: Постановление Правительства СанктПетербурга от 17 декабря 2009 г. №1448 // Вестник Администрации Санкт-Петербурга. - 2010. - 29 янв.

9 Временная методика проведения ежегодного комплексного антикоррупционного мониторинга эффективности принимаемых органами исполнительной власти Ставропольского края мер противодействия коррупции, утвержденная решением рабочей группы по реализации Закона Ставропольского края от 4 мая 2009 г. №25-кз «О противодействии коррупции в Ставропольском крае» от 27 декабря 2012 г. // Документ официально опубликован не был и находится в личном архиве автора.
} 
ционного мониторинга следует признать приказы региональных органов исполнительной власти Ульяновской ${ }^{10}$ и Свердловской ${ }^{11}$ областей, а также города Санкт-Петербурга ${ }^{12}$. Однако в большинстве субъектов РФ вопросы правового регулирования проведения антикоррупционного мониторинга на ведомственном уровне остаются открытыми, в лучшем случае назначается должностное лицо, ответственное за подготовку и предоставление необходимой информации уполномоченному органу.

В качестве примеров муниципального реагирования на участие в проведении регионального антикоррупционного мониторинга следует признать ряд нормативных правовых актов муниципальных обра-

10 Об утверждении методики мониторинга и графика проведения проверок результативности мер противодействия коррупции в Департаменте культуры и архивного дела Ульяновской области и в подведомственных учреждений: Приказ Департамента культуры и архивного дела Ульяновской области от 11 июня 2009 г. №193 // Документ официально не опубликован и находится в личном архиве автора.

11 Об антикоррупционном мониторинге и порядке его проведения Министерством общего и профессионального образования Свердловской области: Приказ Министерства общего и профессионального образования Свердловской области от 13 ноября 2009 г. №339-л; Об антикоррупционном мониторинге в Управлении архивами Свердловской области и порядок его проведения: Приказ Управления архивами Свердловской области от 16 ноября 2009 г. №01-07166 ; О мониторинге состояния и эффективности противодействия коррупции (антикоррупционном мониторинге) в органах социальной защиты населения Свердловской области: Приказ Министерства социальной защиты населения Свердловской области от 28 марта 2011 г. №196 // Документы официально не были опубликованы и находятся в личном архиве автора.

12 Об утверждении Положения о порядке формирования и предоставления Комитетом по делам записи актов гражданского состояния сведений по показателям и информационных материалов антикоррупционного мониторинга: Приказ Комитета по делам записи актов гражданского состояния Санкт-Петербурга от 7 февраля 2011 г. №11; О порядке предоставления Комитетом по транспортно-транзитной политике информации по разделам антикоррупционного мониторинга: Приказ Комитета по транспортно-транзитной политике Санкт-Петербурга от 15 февраля 2011 г. №7 // Документы официально опубликованы не были и находятся в личном архиве автора. зований Владимирской ${ }^{13}$ и Свердловской ${ }^{14}$ областей и Краснодарского ${ }^{15}$ края. В муниципальных образованиях других субъектов РФ, даже там где антикоррупционный мониторинг предусмотрен региональным антикоррупционным законодательством правовое регулирование организации и проведения антикоррупционного мониторинга осуществляется избирательно.

Как показывает проведенный нами сравнительно-правовой анализ региональных и муниципальных нормативных правовых актов, существующая региональная практика правового регулирования организа-

13 См., напр.: О проведении антикоррупционного мониторинга на территории Киржачского района: Постановление главы Киржачского района от 04.08.2009 № 940 (в ред. от 30.03.2011 №06) // Красное знамя. - 2009. - 11 авг;; О порядке проведения антикоррупционного мониторинга в Вязниковском районе: Постановление администрации муниципального образования Вязниковский район Владимирской области от 31.07.2012 № 886 // Маяк. - 2012. - 14 авг; Об утверждении Положения об антикоррупционном мониторинге в Гороховецком районе: Постановление администрации Гороховецкого района от 18.06.2012 № 853 // Новая жизнь. - 2012. - 22 июня.

14 См., напр.: О мониторинге состояния и эффективности противодействия коррупции (антикоррупционном мониторинге) в муниципальном образовании “город Екатеринбург”: Постановление Главы Екатеринбурга от 15.04.2009 № 1249 // Вечерний Екатеринбург. - 2009. - 17 апр.; О мониторинге состояния и эффективности противодействия коррупции (антикоррупционном мониторинге) в Горноуральском городском округе Решение Думы Горноуральского городского округа от 24.02.2012 № 58/9// Пригородная газета. - 2012. - 2 марта; О мониторинге состояния и эффективности противодействия коррупции (антикоррупционный мониторинг) на территории АГО: Постановление Администрации Артинского городского округа от 08.06.2011 № 478 // Артинские вести. - 2011. - 21 июня.

15 См., напр.: Об утверждении методики мониторинга коррупционных рисков структурных подразделений, отраслевых (функциональных) и территориальных органов администрации муниципального образования город Новороссийск для определения перечня должностей, в наибольшей степени подверженных риску коррупции, и об отмене постановлений администрации муниципального образования город Новороссийск от 6 сентября 2010 г. № 3118, от 1 апреля 2010 г. № 919: Постановление администрации муниципального образования город Новороссийск от 24.03.2011 № 1261 // Новороссийские вести. - 2011. - 13 апр.; Об утверждении Методики мониторинга коррупционных рисков в администрации муниципального образования Выселковский район для определения перечня должностей, в наибольшей степени подверженных риску коррупции: Постановление администрации муниципального образования Выселковский район Краснодарского края от 20.01.2010 // Власть Советов. - 2010. 30 янв.; Об утверждении мониторинга восприятия уровня коррупции и методики мониторинга коррупционных рисков в администрации муниципального образования Темрюкский район: Постановление администрации муниципального образования Темрюкский район Краснодарского края от 03.08.2012 № 1626 // Тамань. - 2012. - 15 авг. 
ции и проведения антикоррупционного мониторинга является противоречивой и требует его существенной корректировки или изменения. Такие изменения необходимы как для повышения эффективности системы регионального и муниципального антикоррупционного мониторинга, так и для формирования единой национальной системы антикоррупционного мониторинга.

Следовательно, создание единообразной, компактной и эффективной системы нормативно-правового регулирования национального, регионального, муниципального антикоррупционного мониторинга потребует разработки модельных (типовых) нормативных правовых актов по его организации и проведения. Учитывая, что традиционно типовые нормативные правовые акты подготавливаются федеральными органами исполнительной власти и утверждаются президиумом Совета при Президенте РФ по противодействию коррупции, то и модельные нормативные правовые акты по организации и проведению регионального антикоррупционного мониторинга должны разрабатываться и утверждаться по той же правотворческой процедуре и технологии.

Изложенное позволяет сделать вывод о том, что в целях совершенствования организационно-правовых основ антикоррупционного мониторинга в субъектах РФ необходимо создать группу модельных кодифицированных нормативных правовых актов по его организации и проведению. Это позволит поддерживать единый подход к оценке состояния коррупции, её причин и эффективности мер противодействия коррупции в различных регионах и муниципальных образованиях и построить единую национальную систему антикоррупционного мониторинга.

\section{Библиографический список:}

1. О мерах по организации и проведению мониторинга эффективности деятельности органов исполнительной власти Республики Татарстан, территориальных органов федеральных органов исполнительной власти по Республике Татарстан, органов местного самоуправления муниципальных районов и городских округов Республики Татарстан по реализации антикоррупционных мер на территории Республики Татарстан: Указ Президента Республики Татарстан от 23 марта 2011 г. №УП-148 // Сборник постановлений и распоряжений Кабинета Министров Республики Татарстан и нормативных актов республиканских органов исполнительной власти. - 2011. - №11. - №18. - Ст. 0636.

2. О мониторинге состояния и эффективности противодействия коррупции (антикоррупционном мониторинге) в муниципальном образовании «город Екатеринбург»: Постановление Главы Екатеринбурга от 15.04.2009 № 1249 // Вечерний Екатеринбург. - 2009. - 17 апр.

3. О мониторинге состояния и эффективности противодействия коррупции (антикоррупционном мониторинге) в Горноуральском городском округе Решение Думы Горноуральского городского округа от 24.02.2012 N 58/9 // Пригородная газета. - 2012. - 2 марта.

4. О мониторинге состояния и эффективности противодействия коррупции (антикоррупционный мониторинг) на территории АГО: Постановление Администрации Артинского городского округа от 08.06.2011 № 478 // Артинские вести. - 2011. - 21 июня.

5. О порядке осуществления антикоррупционного мониторинга: Постановление Правительства Республики Дагестан от 20 апреля 2012 г. №119 // Собрание законодательства Республики Дагестан. - 2012. - №8. - Ст. 312.

6. О порядке осуществления комиссией по противодействию коррупции в Ростовской области антикоррупционного мониторинга: Постановление Правительства Ростовской области от 19 апреля 2012 г. №300 // Наше время. - 2012. - 3 мая.

7. О порядке проведения антикоррупционного мониторинга в Вязниковском районе: Постановление администрации муниципального образования Вязниковский район Владимирской области от 31.07 .2012 № 886 // Маяк. - 2012. - 14 авг.

8. О Порядке проведения антикоррупционного мониторинга в Санкт-Петербурге: Постановление Правительства Санкт-Петербурга от 17 декабря 2009 г. №1448 // Вестник Администрации Санкт-Петербурга. - 2010. 29 янв.

9. О проведении антикоррупционного мониторинга на территории Киржачского района: Постановление главы Киржачского района от 04.08.2009 № 940 (в ред. от 30.03.2011 №06) // Красное знамя. - 2009. - 11 авг.

10. Об организации и проведении мониторинга эффективности деятельности органов исполнительной власти Республики Татарстан, территориальных органов федеральных органов исполнительной власти по Республике Татарстан, органов местного самоуправления муниципальных районов и городских округов Республики 
Татарстан по реализации антикоррупционных мер на территории Республики Татарстан: Постановление Кабинета Министров Республики Татарстан от 10 июня 2011 г. №463 // Сборник постановлений и распоряжений Кабинета Министров Республики Татарстан и нормативных актов республиканских органов исполнительной власти. - 2011. - №25. - Ст. 1081.

11. Об осуществлении антикоррупционного мониторинга соблюдения требований законодательства о противодействии коррупции: Указ Губернатора Ярославской области от 7 июня 2012 г. № 256 // Документ-Регион. 2012. - 13 июня.

12. Об осуществлении антикоррупционного мониторинга соблюдения требований законодательства о противодействии коррупции: Постановление Правительства области от 12.09.2012 № 888-п // Документ-Регион. 2012. - 21 сентяб.

13. Об утверждении Методики мониторинга коррупционных рисков в администрации муниципального образования Выселковский район для определения перечня должностей, в наибольшей степени подверженных риску коррупции: Постановление администрации муниципального образования Выселковский район Краснодарского края от 20.01.2010 // Власть Советов. - 2010. - 30 янв.

14. Об утверждении методики мониторинга коррупционных рисков структурных подразделений, отраслевых (функциональных) и территориальных органов администрации муниципального образования город Новороссийск для определения перечня должностей, в наибольшей степени подверженных риску коррупции, и об отмене постановлений администрации муниципального образования город Новороссийск от 6 сентября 2010 г. № 3118, от 1 апреля 2010 г. №919: Постановление администрации муниципального образования город Новороссийск от 24.03.2011 №1261 // Новороссийские вести. - 2011. - 13 апр.

15. Об утверждении методики проведения антикоррупционного мониторинга цен на товары, услуги и при осуществлении закупок для нужд Ярославской области: Постановление Правительства Ярославской области от 26 августа 2011 г. №624 // Документ-Регион. - 2011. - 6 сентяб.;

16. Об утверждении мониторинга восприятия уровня коррупции и методики мониторинга коррупционных рисков в администрации муниципального образования Темрюкский район: Постановление администрации муниципального образования Темрюкский район Краснодарского края от 03.08.2012 №1626 // Тамань. - 2012. 15 авг.

17. Об утверждении Положения об антикоррупционном мониторинге в Гороховецком районе: Постановление администрации Гороховецкого района от 18.06.2012 №853 // Новая жизнь. - 2012. - 22 июня.

\section{References (transliteration):}

1. O merah po organizacii i provedeniyu monitoringa effektivnosti deyatel'nosti organov ispolnitel'noy vlasti Respubliki Tatarstan, territorial'nyh organov federal'nyh organov ispolnitel'noy vlasti po Respublike Tatarstan, organov mestnogo samoupravleniya municipal'nyh rayonov i gorodskih okrugov Respubliki Tatarstan po realizacii antikorrupcionnyh mer na territorii Respubliki Tatarstan: Ukaz Prezidenta Respubliki Tatarstan ot 23 marta 2011 g. №UP-148 // Sbornik postanovleniy i rasporyazheniy Kabineta Ministrov Respubliki Tatarstan i normativnyh aktov respublikanskih organov ispolnitel’noy vlasti. - 2011. - №11. - №18. - St. 0636.

2. O monitoringe sostoyaniya i effektivnosti protivodeystviya korrupcii (antikorrupcionnom monitoringe) $v$ municipal’nom obrazovanii "gorod Ekaterinburg»: Postanovlenie Glavy Ekaterinburga ot 15.04.2009 № 1249 // Vecherniy Ekaterinburg. - 2009. - 17 apr.

3. O monitoringe sostoyaniya i effektivnosti protivodeystviya korrupcii (antikorrupcionnom monitoringe) v Gornoural'skom gorodskom okruge Reshenie Dumy Gornoural'skogo gorodskogo okruga ot 24.02.2012 № 58/9 // Prigorodnaya gazeta. - 2012. - 2 marta.

4. O monitoringe sostoyaniya i effektivnosti protivodeystviya korrupcii (antikorrupcionnyy monitoring) na territorii AGO: Postanovlenie Administracii Artinskogo gorodskogo okruga ot 08.06.2011 № 478 // Artinskie vesti. — 2011. 21 iyunya.

5. O poryadke osuschestvleniya antikorrupcionnogo monitoringa: Postanovlenie Pravitel'stva Respubliki Dagestan ot 20 aprelya 2012 goda №119 // Sobranie zakonodatel'stva Respubliki Dagestan. — 2012. — №8. - St.312.

6. O poryadke osuschestvleniya komissiey po protivodeystviyu korrupcii v Rostovskoy oblasti antikorrupcionnogo monitoringa: Postanovlenie Pravitel'stva Rostovskoy oblasti ot 19 aprelya 2012 g. №300 // Nashe vremya. - 2012. 3 maya. 
Административное и муниципальное право 7 (67) • 2013

7. O poryadke provedeniya antikorrupcionnogo monitoringa v Vyaznikovskom rayone: Postanovlenie administracii municipal'nogo obrazovaniya Vyaznikovskiy rayon Vladimirskoy oblasti ot 31.07.2012 № 886 // Mayak. — 2012. — 14 avg.

8. O Poryadke provedeniya antikorrupcionnogo monitoringa v Sankt-Peterburge: Postanovlenie Pravitel'stva SanktPeterburga ot 17 dekabrya 2009 g. №1448 // Vestnik Administracii Sankt-Peterburga. - 2010. - 29 yanv.

9. O provedenii antikorrupcionnogo monitoringa na territorii Kirzhachskogo rayona: Postanovlenie glavy Kirzhachskogo rayona ot 04.08.2009 № 940 (v red. ot 30.03.2011 №06) // Krasnoe znamya. - 2009. - 11 avg.

10. Ob organizacii i provedenii monitoringa effektivnosti deyatel'nosti organov ispolnitel'noy vlasti Respubliki Tatarstan, territorial'nyh organov federal'nyh organov ispolnitel'noy vlasti po Respublike Tatarstan, organov mestnogo samoupravleniya municipal'nyh rayonov i gorodskih okrugov Respubliki Tatarstan po realizacii antikorrupcionnyh mer na territorii Respubliki Tatarstan: Postanovlenie Kabineta Ministrov Respubliki Tatarstan ot 10 iyunya 2011 g. №463 // Sbornik postanovleniy i rasporyazheniy Kabineta Ministrov Respubliki Tatarstan i normativnyh aktov respublikanskih organov ispolnitel’noy vlasti. - 2011. - №25. - St. 1081.

11. Ob osuschestvlenii antikorrupcionnogo monitoringa soblyudeniya trebovaniy zakonodatel'stva o protivodeystvii korrupcii: Ukaz Gubernatora Yaroslavskoy oblasti ot 7 iyunya 2012 g. № 256 // Dokument-Region. - 2012. - 13 iyunya.

12. Ob osuschestvlenii antikorrupcionnogo monitoringa soblyudeniya trebovaniy zakonodatel'stva o protivodeystvii korrupcii: Postanovlenie Pravitel'stva oblasti ot 12.09.2012 № 888-p // Dokument-Region. - 2012. - 21 sentyab.

13. Ob utverzhdenii Metodiki monitoringa korrupcionnyh riskov v administracii municipal'nogo obrazovaniya Vyselkovskiy rayon dlya opredeleniya perechnya dolzhnostey, v naibol'shey stepeni podverzhennyh risku korrupcii: Postanovlenie administracii municipal'nogo obrazovaniya Vyselkovskiy rayon Krasnodarskogo kraya ot 20.01.2010 // Vlast' Sovetov. - 2010. - 30 yanv.

14. Ob utverzhdenii metodiki monitoringa korrupcionnyh riskov strukturnyh podrazdeleniy, otraslevyh (funkcional'nyh) i territorial'nyh organov administracii municipal'nogo obrazovaniya gorod Novorossiysk dlya opredeleniya perechnya dolzhnostey, $v$ naibol'shey stepeni podverzhennyh risku korrupcii, i ob otmene postanovleniy administracii municipal'nogo obrazovaniya gorod Novorossiysk ot 6 sentyabrya 2010 goda N 3118, ot 1 aprelya 2010 g. №919: Postanovlenie administracii municipal’nogo obrazovaniya gorod Novorossiysk ot 24.03.2011 №1261 // Novorossiyskie vesti. - 2011. - 13 apr.

15. Ob utverzhdenii metodiki provedeniya antikorrupcionnogo monitoringa cen na tovary, uslugi i pri osuschestvlenii zakupok dlya nuzhd Yaroslavskoy oblasti: Postanovlenie Pravitel’stva Yaroslavskoy oblasti ot 26 avgusta 2011 g. №624 // Dokument-Region. - 2011. - 6 sentyab.

16. Ob utverzhdenii monitoringa vospriyatiya urovnya korrupcii i metodiki monitoringa korrupcionnyh riskov $v$ administracii municipal'nogo obrazovaniya Temryukskiy rayon: Postanovlenie administracii municipal'nogo obrazovaniya Temryukskiy rayon Krasnodarskogo kraya ot 03.08.2012 №1626 // Taman’. - 2012. - 15 avg.

17. Ob utverzhdenii monitoringa vospriyatiya urovnya korrupcii i metodiki monitoringa korrupcionnyh riskov $v$ administracii municipal'nogo obrazovaniya Temryukskiy rayon: Postanovlenie administracii municipal'nogo obrazovaniya Temryukskiy rayon Krasnodarskogo kraya ot 03.08.2012 №1626 // Taman'. - 2012. - 15 avg. 